\title{
LA SALUD COMPONENTE ESENCIAL EN LA CONSTRUCCIÓN DE PAZ
}

\author{
HEALTH ESSENTIAL COMPONENT IN THE CONSTRUCTION OF PEACE
}

Álvaro A Sánchez Caraballo'

Lejos de cualquier duda, un pensamiento plasmado en programas de salud renovados y ejecutados en la comunidad, pueden favorecer en gran medida el mejoramiento de la calidad de vida y la coexistencia pacífica en el país. Esto exige pasar, de la conceptualización académica y mental del derecho a la salud, al cumplimiento del mismo en la práctica diaria; lo que a su vez revalorizaría la depauperada concepción de la vida ante el menosprecio de la misma. Implicaría asimismo, reconocer que el bienestar humano no solo tiene facetas psicosociales influidas por aspectos políticos, económicos, educativos y laborales, sino también que tiene una dimensión ambiental, lo que introduce el concepto de la necesidad de un estado de equilibrio de la vida humana con el ambiente que le rodea.

Ante este panorama, es imposible soslayar estos desafíos o creer que se pueden enfrentar sin el concurso de distintos actores. Por lo tanto, es esencial el papel que pueden desempeñar las instituciones donde se forman las nuevas generaciones, desde la más temprana edad hasta la educación superior. Igualmente es importante el aporte de los centros de pensamiento, de los académicos de las facultades de salud, y de todo aquello que gravita alrededor de ellos como la investigación. Contextualizando lo anterior, en el hecho de que la salud es un derecho humano fundamental, es fácil romper con el pensamiento de que esta es una dádiva del Estado para con sus súbditos o una concesión del mismo para con ellos. Esta ruptura permite ubicar la salud en un plano superior con respecto a la dignidad humana, algo ineludible en lo que a su prestación se refiere; permitiendo paralelamente deshacer el inhumano enfoque reduccionista de una medicina curativa en aras de la prevención.

De acuerdo con lo hasta aquí expuesto, se hace imprescindible un buen sistema de salud. Entendido este, como el modo en que la sociedad mediante el Estado garantiza el derecho a la salud, organizando, prestando y financiando los distintos servicios de salud que necesita todo miembro de la sociedad. Visto así, el Sistema de Salud es protagonista fundamental en la edificación de una sociedad en paz. Sin embargo, el que tiene Colombia se ha mostrado incapaz de prestar la atención oportuna y adecuada ante las crecientes necesidades en prevención y tratamiento de las enfermedades. Tal incapacidad intranquiliza a la ciudadanía y le resta legitimidad al Estado, haciéndolo ver como un ente incompetente que no responde adecuadamente a los antiguos o nuevos requerimientos en salud, por lo tanto un cambio de fondo es condición necesaria para el anhelado objetivo de un nuevo país.

${ }^{1}$ Editor Revista Avances en Salud 